Canadian Oncology

Nursing Journal

Revue canadienne

de soins infirmiers

en oncologie

Volume 30, Issue 3 • Summer 2020

elSSN: 2368-8076 


\title{
Ambulatory care unit role optimization for the specialized oncology nurse
}

\author{
by Andrea Knox
}

\section{ABSTRACT}

While the role of the specialized oncology nurse in treatment and symptom management is well established, the role in the outpatient setting is not as well defined. Increasing patient complexity, the rising incidence of cancer, and evolving treatment regimens is pressing $B C$ Cancer to reassess its Ambulatory Care Unit (ACU) model of care to better meet patient needs. The purpose of this project was to identify and map the specific role and functional tasks of nurses working in the ACU to specialty competencies for the oncology nurse. A baseline functional role elements list and role-competency map were developed from clinical observations and focus group sessions. This work will help provide role clarity and enable nursing to articulate both the scope of practice and the specialty competencies required to best meet the needs of our patients in the ACU setting. The results of this project can be utilized in strategic and operational planning discussions focused on improving health services for patients and supporting the continued professional development of front-line staff. The approaches utilized may be of interest to others who wish to apply similar methods in their own cancer settings.

\section{INTRODUCTION AND BACKGROUND}

$\mathrm{O}$ ncology nurses at BC Cancer work in a variety of inpatient and outpatient clinics to support patients across the trajectory of the cancer care journey. While the role of the specialized oncology nurse in administering treatments and managing side effects has been clearly established in BC Cancer (BC Cancer, 2018), the role of the nurse in the outpatient Ambulatory Care Unit (ACU) is not as well defined. The complexity of the outpatient oncology patient population, increasing incidence of cancer (Canadian Cancer Society, 2018) and continual emergence of novel treatment regimens are pressing BC Cancer to reassess the ACU model of care.

In 2018, work began on a multiphased project to understand patient needs and nursing's role in the ACU. For phase one, the Care Team Design Initiative was piloted to identify the priority care needs of the oncology patient population, and current staff nurse perceptions of actual scope of practice (ASCOP) in the clinical context (BC Children's

\author{
AUTHOR NOTE \\ Andrea Knox, RN, BSN, MSN, CON(c) \\ Senior Practice Leader, Nursing \\ BC Cancer-Kelowna \\ 1015 Tataryn Rd, Kelowna, BC, V1X1N6 \\ 250-258-4928 \\ aknox@bccancer.bc.ca
}

DOI:10.5737/23688076303159168
\& Women's Hospital, BC Children's \& Women's Hospital, 2018). Results of the patient assessment identified that needs in the ambulatory care environment are predictable and stable (BC Children's \& Women's Hospital, BC Children's \& Women's Hospital, 2018). The ASCOP assessment revealed that nurses perceived their scope of practice as lower across certain domains of care in the ACU context (BC Children's \& Women's Hospital, 2018).

While the patient needs and staff nurse perceptions of scope of practice were clearly identified for BC Cancer Kelowna through the Care Team Design Initiative, further work was needed to clearly define nursing's role in the ACU model of care. Currently, there is significant variation in the staff mix and optimization of nurses' scope of practice in the ACU environment across the regional cancer centres. The variation encompasses clinics staffed with only care aids to mixed models that utilize a combination of care aid, Licensed Practical Nurse (LPN) and Registered Nurse (RN) positions. The absence of standardization across the centres has resulted in a lack of role clarity both within the nursing discipline and across the interdisciplinary team. Defining and optimizing the role of nursing in the ACU environment will help provide role clarity and enable nursing to articulate both the scope of practice and the specialty competencies required to best meet the needs of patients and families from a quality and safety perspective.

\section{PURPOSE}

The scope of practice for RNs and LPNs in British Columbia (BC) is broadly defined by the BC College of Nursing Professionals (BCCNP, 2018a-d) based on the requirements outlined in the Health Professions Act (Health Professions Act, 2018a-b). RN and LPN scope are further refined by employer policies and individual competency. In the field of oncology, the Canadian Association of Nurses in Oncology (CANO/ACIO) has also developed practice standards to identify the specialty competencies required for nurses caring for cancer patients. Identified as phase two, the purpose of the work reported in this paper was to identify and map the specific role and functional tasks of nurses working in the ACU to specialty competencies for the oncology nurse defined by the Canadian Association of Nurses in Oncology (Canadian Association of Nurses in Oncology, 2006).This quality improvement (QI) project was acknowledged as a continuation of the Care Team Design Initiative and lays the foundation for future phases of work including resource intensity weighting and specialty education planning specific to the ACU nursing role. This paper presents the findings from the initial literature review and the project work aimed at optimizing the role of the 
oncology nurse in the ambulatory setting. The approaches utilized may be of interest to others who wish to conduct a similar project in their own settings.

\section{ARECCI ASSESSMENT FOR THE PROJECT}

Currently there is no formal requirement for ethical review of quality improvement (QI) projects within BC Cancer, but it was recognized that this lack of organizational requirement should not equate to a lack of consideration of fundamental ethical principles (Hagen et al., 2007). To support ethical review, an assessment was completed using the Alberta Research Ethics Community Consensus Initiative (ARECCI) instrument. The final ARECCI score was identified as 2, placing this proposed project in the category of minimal risk. As a result, it was determined that ethical approval was not required for this project based on the minimal risk and strong alignment with the definition of QI.

\section{LITERATURE REVIEW}

A review of the literature was completed to provide an evidence-based foundation for this quality improvement project. The purpose of the review was to explore current research and trends in defining the role and competencies of the oncology nurse in the ambulatory setting.

\section{Methods}

The MedLine, CINAHL and PubMed databases were searched for current and relevant literature using the MeSH terms "oncology nursing AND role AND outpatient OR ambulatory AND competency*”. A brief manual search of the CANO/ACIO and British Columbia College of Nursing Professionals (BCCNP) websites was also conducted for literature related to the previously identified search terms. The CANO/ACIO website was selected for inclusion in the search strategy, as this professional association is nationally and internationally known for its work in developing standards, competencies and resources specific to the oncology nursing specialty. The BCCNP website was also manually searched for relevant literature as it sets provincial standards and scopes of practice for RN's and LPN's in the province of BC.

The literature search inclusion criteria were limited to peer-reviewed, full-text, English-only articles, published between 2013 and 2018. It was noted that the limits placed on the literature search, such as English only with full text, may have inadvertently excluded some relevant published works. However, the time and cost associated with translation of non-English articles were beyond the scope of this project. It must also be noted that the exclusion of literature prior to 2013 may have removed earlier published works relevant to the role of the oncology nurse in ambulatory care.

\section{Results}

The manual and database literature searches resulted in the identification of 131 articles for preliminary screening, which was reduced to 115 after the removal of 16 duplicates. Initial screening by title and abstract review resulted in the exclusion of 96 articles. A full-text review was then completed to screen the remaining 19 articles for relevancy, resulting in the exclusion of three additional articles. Fifteen eligible articles were identified for inclusion comprising a mix of quantitative or mixed method research designs (Azar et al., 2017; BC Children's \& Women's Hospital, 2018; Berglund et al., 2015; Kaunonen et al., 2015; Lee et al., 2014), executive summaries (Haas et al., 2016; More, 2017), an expert panel (Haas et al., 2013), professional and practice standards (BCCNP, 2018a; BCCNP, 2018b; CANO/ACIO, 2006; CANO/ACIO, 2017; CANO/ACIO, 2018), and documents pertaining to RN and LPN scope of practice in BC (BCCNP, 2018c; BCCNP, 2018d).

\section{Findings}

As only five articles identified for inclusion in the literature review represented formal research on the competency-based role of oncology nursing in ambulatory care, a mix of empirical

\begin{tabular}{|c|c|}
\hline \multicolumn{2}{|c|}{$\begin{array}{l}\text { Table 1: CANO-ACIO Standards of Care. Adapted from the } \\
\text { CANO-ACIO Practice Standards and Competencies for the } \\
\text { Specialized Oncology Nurse (2006) }\end{array}$} \\
\hline $\begin{array}{l}\text { Individualized and } \\
\text { Holistic Care }\end{array}$ & $\begin{array}{l}\text { Cancer patients and their families are } \\
\text { entitled to individualized, holistic care }\end{array}$ \\
\hline $\begin{array}{l}\text { Family-Centered } \\
\text { Care }\end{array}$ & $\begin{array}{l}\text { Cancer patients and their families are } \\
\text { entitled to family-centered care that is } \\
\text { respectful of family resources and coping } \\
\text { style }\end{array}$ \\
\hline $\begin{array}{l}\text { Self-Determination } \\
\text { and Decision-Making }\end{array}$ & $\begin{array}{l}\text { Cancer patients and their families have } \\
\text { the right to access information and make } \\
\text { decisions about their care }\end{array}$ \\
\hline $\begin{array}{l}\text { Navigating the } \\
\text { System }\end{array}$ & $\begin{array}{l}\text { Cancer patients and their families are } \\
\text { entitled to assistance in navigating the } \\
\text { healthcare system across the cancer care } \\
\text { continuum }\end{array}$ \\
\hline $\begin{array}{l}\text { Coordinated } \\
\text { Continuous Care }\end{array}$ & $\begin{array}{l}\text { Cancer patients and their families are } \\
\text { entitled to care that is coordinated } \\
\text { among providers across the cancer care } \\
\text { continuum }\end{array}$ \\
\hline $\begin{array}{l}\text { Supportive } \\
\text { Therapeutic } \\
\text { Relationship }\end{array}$ & $\begin{array}{l}\text { Cancer patients and their families are } \\
\text { entitled to a knowledgeable, supportive } \\
\text { and therapeutic relationship with } \\
\text { healthcare providers across the trajectory } \\
\text { of their cancer journey }\end{array}$ \\
\hline Evidence-Based Care & $\begin{array}{l}\text { Cancer patients and their families are } \\
\text { entitled to care that is based on research } \\
\text { and best practice }\end{array}$ \\
\hline Professional Care & $\begin{array}{l}\text { Cancer patients and their families are } \\
\text { entitled to ethical and professional care } \\
\text { that meets legislative requirements }\end{array}$ \\
\hline Leadership & $\begin{array}{l}\text { Cancer patients and their families are } \\
\text { entitled to care within a healthcare } \\
\text { system that has professional, patient- } \\
\text { focused leadership }\end{array}$ \\
\hline
\end{tabular}


studies and theoretical papers were included to provide a representative overview of the current evidence. Three main themes emerged from the literature related to the role of the oncology nurse in outpatient care: dimensions of patient-centred care, professional practice in oncology nursing, and nursing and the interdisciplinary team.

\section{Dimensions of Patient-Centred Care}

The first theme, dimensions of patient centered care, encompasses patient-centred standards of care and patient perceptions of care (Azar et al., 2017; Berglund et al., 2015; CANO/ ACIO, 2006; Haas et al., 2013; Haas et al., 2016; More, 2017). Client-focused provision of service is a foundational standard present in the RN and LPN professional standards in BC, providing clear direction that nurses work with other members of the interdisciplinary team, as required to provide care that is in the best interest of clients (BCCNP, 2018a; BCCNP, 2018b). For the specialized oncology nurse, CANO/ACIO identified nine additional standards, which clearly articulate the care patients and their families are entitled to across the cancer care continuum (Table 1) (CANO/ACIO, 2006).

Haas, Swan and Hayes (2013) presented similar patientcare dimensions for nurses to support care coordination and transition management in the ambulatory setting. In particular, the dimension of coordinated continuous care was also identified as important from the perspective of patients (Berglund et al., 2015). Continuity of care, which can be related to informational, relational and care management needs, was perceived by patients to be most effective in the presence of nurse coordinator or nurse navigator roles in the outpatient setting. Azar et al. (2017) measured the relationship of teamwork and patients' perceptions of care and revealed elevated scores in relational coordination for nurse coordinators, a role centred on continuous care coordination, which correlated with positive patient perceptions of care. Hence, there is consistent evidence in the current literature regarding dimensions of patient-centred cancer care (BCCNP, 2018a; BCCNP, 2018b; CANO-ACIO, 2006; Haas et al., 2013), which align with patient perceptions of care delivered by outpatient oncology nurses (Azar et al., 2017; Berglund et al., 2015).

\section{Professional Practice in Oncology Nursing}

The second identified theme focused on the professional practice of oncology nursing. Specifically, it included the required competencies and standards of practice derived from the professional standards of care and patient-care dimensions (BCCNP, 2018a; BCCNP, 2018b; CANO/ACIO, 2006; Haas et al., 2013). Under the nine CANO/ACIO standards of care (Table 1), seven practice standards and supporting competencies were established for the specialized oncology nurse: "comprehensive health assessment, supportive and therapeutic relationships, management of cancer symptoms and treatment side effects, teaching and coaching, facilitating continuity of care/navigating the system, decision making and advocacy, and professional practice and leadership" (CANO/ACIO, 2006, p. 1). The nine standards of care (Table 1) and seven practice standards have also been embedded in the CANO/ACIO sub-specialty standards for radiation and systemic therapy (CANO/ACIO, 2017; CANO/ACIO, 2018). These documents provide the standards for practice, education and continuing competence for nurses caring for patients receiving radiation or systemic therapy in Canada (CANO/ACIO, 2017; CANO/ACIO, 2018). Haas, Swan and Hayes (2013) convened an expert panel to develop competencies specific to the ambulatory nursing role. While not oncology specific, the nine patient-care dimensions identified were supported by competencies that align with the CANO/ACIO practice standards. This demonstrates congruency between the professional practice of oncology nurses and the literature concerning professional nursing practice in the outpatient setting. (CANO/ACIO, 2006; CANO/ACIO, 2017; CANO/ACIO, 2018; Haas et al., 2013).

\section{Nursing and the Interdisciplinary Team}

The third theme centred on the oncology nurse as a member of the interdisciplinary team, specifically the importance of a highly collaborative, team-based model of care with the right staff mix to best meet patient needs (Azar et al., 2017; CANO/ACIO, 2006; Haas et al., 2013; Haas et al., 2016; Kaunonen et al., 2015; Lee et al., 2014; More, 2017) . In general, oncology nurses and physicians rate the quality of their interprofessional interactions high in the outpatient setting (Lee et al., 2014), with the role of the nurse in facilitating communication and coordinating care across the interprofessional team emphasized as a key driver for successful communication (Azar et al., 2017; Haas et al., 2013; Lee, et al., 2014; More, 2017). However, role clarity between team members was also identified as an important factor to facilitate, as it can enhance the overall effectiveness of the interdisciplinary team (Haas et al., 2013; Haas et al., 2016). To mitigate potential issues with role clarity, inclusion of front-line staff nurses in the development of the ambulatory model of care is recommended, to help leaders identify the right healthcare providers to match patient needs (Haas et al., 2016; Kaunonen et al., 2015).

\section{Gap Analysis}

There was a notable lack of formal research on optimizing the role of the oncology nurse in the ambulatory setting. Most articles in this review were of a non-research variety. Competencies and practice standards specific to the oncology nursing specialty in the Canadian context are available to guide the proposed role optimization work and are consistent with recommendations found across the current literature. Similarly, literature exploring the role of the nurse in the interdisciplinary team, patient-care dimensions, and patient perceptions of oncology nursing care, demonstrated congruency. Thus, further research specific to optimizing the role of the oncology nurse in the ambulatory setting was recommended. This quality improvement project was designed to address the gap identified in the literature and advance the practice of oncology nurses at BC Cancer.

\section{PROJECT CONTEXT}

The project work aimed at optimizing the role of the oncology nurse in the ambulatory setting was focused in a specific clinical context, the ACU. This unit is staffed by an 


\section{Table 2: Interview Guides}

\section{Focus Group 1: Interview Guide}

Purpose: To revise and validate the baseline functional role elements list with ACU nursing staff

\section{Introduction}

- Complete group introductions and present purpose of the focus group

- Provide participants with an overview of the focus group agenda

- Provide an overview of the proposed baseline functional role elements list

1. Reflecting on the role of the Systemic Therapy (ST) ACU nurse in new patient appointment visits, are all the activities you currently perform captured on the proposed list?

a. If not, what activities are missing?

2. Are there any activities that you currently do not perform in the role of the ACU nurse supporting new patient appointments due to time or resource limitations that you feel should be included on this list?

a. If yes, what activities would you like to add?

3. Reflecting on the role of the Radiation Therapy (RT) ACU nurse in new patient appointment visits, are all the activities you currently perform captured on the proposed list?

a. If not, what activities are missing?

4. Are there any activities that you currently do not perform in the role of the ACU nurse supporting new patient appointments due to time or resource limitations that you feel should be included on this list?

a. If yes, what activities would you like to add?

5. Reflecting on the role of the ST ACU nurse in active treatment appointments, are all the activities you currently perform captured on the proposed list?

a. If not, what activities are missing?

6. Are there any activities that you currently do not perform in the role of the ACU nurse supporting new patient appointments due to time or resource limitations that you feel should be included on this list?

a. If yes, what activities would you like to add?

7. Reflecting on the role of the ST ACU in follow-up appointment visits, are all the activities you currently perform captured on the proposed list?

a. If not, what activities are missing?

8. Are there any activities that you currently do not perform in the role of the ACU nurse supporting new patient appointments due to time or resource limitations that you feel should be included on this list?

a. If yes, what activities would you like to add?

9. Reflecting on the role of the RT ACU nurse in new follow-up appointments, are all the activities you currently perform captured on the proposed list?

a. If not, what activities are missing?

10. Are there any activities that you currently do not perform in the role of the ACU nurse supporting new patient appointments due to time or resource limitations that you feel should be included on this list?

a. If yes, what activities would you like to add?

11. Are there any activities you perform as an $A C U$ nurse that are not directly attached to a specific appointment type which are not reflected in the proposed list?

a. If yes, what activities would you like to add?

12. Are there any activities that you currently do not perform in the role of the ACU nurse due to time or resource limitations which are not directly attached to a specific appointment type that you feel should be included on this list?

a. If yes, what activities would you like to add?

13. Are there any activities on the proposed list that you do not feel are a part of the role of the ACU nurse that you would like to remove?

a. If so, which activities would you like to remove?

14. Do you feel the list accurately reflects the role of the nurse in systemic ACUs?

15. Do you feel the list accurately reflects the role of the nurse in radiation $A C U s$ ?

16. Do you have any additional comments, questions or feedback you would like to share?

continued... 
Focus Group 2: Interview Guide

Purpose: To validate completed role-competency map with ACU nursing staff

\section{Introduction}

- Complete group introductions and present purpose of the focus group

- Provide participants with an overview of the focus group agenda

- Review the previously validated baseline functional role elements list

- Review the CANO Standards and Competencies for the Specialized Oncology Nurse

- Provide an overview of the proposed role-competency map

1. In reviewing the functional role elements for the role of the nurse in a systemic new patient appointment, are the CANO competencies identified for each corresponding activity from the functional role elements list appropriate?

a. If not, what recommendations do you have to revise the map to better align the activity with the CANO competencies?

2. In reviewing the functional role elements for the role of the nurse in a systemic active treatment appointment, are the CANO competencies identified for each corresponding activity from the functional role elements list appropriate?

a. If not, what recommendations do you have to revise the map to better align the activity with the CANO competencies?

3. In reviewing the functional role elements for the role of the nurse in a systemic follow-up appointment, are the CANO competencies identified for each corresponding activity from the functional role elements list appropriate?

a. If not, what recommendations do you have to revise the map to better align the activity with the CANO competencies?

4. In reviewing the functional role elements for the role of the nurse in a radiation new patient appointment, are the CANO competencies identified for each corresponding activity from the functional role elements list appropriate?

a. If not, what recommendations do you have to revise the map to better align the activity with the CANO competencies?

5. In reviewing the functional role elements for the role of the nurse in a radiation follow-up appointment, are the CANO competencies identified for each corresponding activity from the functional role elements list appropriate?

a. If not, what recommendations do you have to revise the map to better align the activity with the CANO competencies?

6. Do you agree with the final proposed role-competency map for the nursing activities previously identified to support systemic therapy new patient appointments?

7. Do you agree with the final proposed role-competency map for the nursing activities previously identified to support radiation therapy new patient appointments?

8. Do you agree with the proposed role-competency map for the nursing activities previously identified to support systemic therapy active treatment appointments?

9. Do you agree with the final proposed role-competency map for the nursing activities previously identified to support systemic therapy follow-up appointments?

10. Do you agree with the final proposed role-competency map for the nursing activities previously identified to support systemic therapy follow-up appointments?

11. Do you agree with the final proposed role-competency map for the nursing activities previously identified that are not attached to a specific appointment type?

12. Do you feel the list accurately maps the CANO standards and competencies to the role of the nurse in systemic ACUs?

13. Do you feel the list accurately maps the CANO standards and competencies to the role of the nurse in radiation ACUs?

14. Do you have any additional comments, questions or feedback you would like to share?

interprofessional team including clerical, nursing, pharmacy, General Practitioners in Oncology (GPO), Nurse Practitioners (NPs), and Radiation and Medical Oncologists (RO/MO). Daily staffing of the clinics included five LPNs and two RNs whose primary functions are to assist with clinic flow and provide a varied range of nursing services. Patients are seen in this clinic for new patient consults, active treatment assessment and follow-up appointments after treatment. One hundred and forty-four new patient consults and 563 active treatment and follow-up appointments are booked weekly, with appointment durations ranging from 20-90 minutes. Stakeholder groups identified for this project included oncology patients, BC Cancer-Kelowna nursing staff, BC Cancer-Kelowna leadership team, and Provincial BC Cancer Professional Practice
Nursing. This project was supported and sponsored at the regional and provincial level.

As each of the regional cancer centres operate an ACU clinic, albeit with different models of care and resources, we anticipated the results of this project would have the potential to impact decisions regarding ACU operations across BC Cancer. To avoid duplication of work, linkages were made with key stakeholders at the other BC Cancer sites to facilitate collaboration during the planning, implementation, evaluation and dissemination phases of the project. Various initiatives related to the ACU model of care were identified at other centres; however, the objectives and goal of this project were seen as complementary and would further inform the work underway. 


\section{FACILITATING FACTORS}

In collaboration with the project mentor and sponsor, factors that facilitated the successful completion of project objectives were proactively identified and considered in relation to the overall project plan. Project sponsorship and support at the regional centre level was identified as a critical, and present, facilitating factor to enable access to the ACU clinic and staff. Likewise, support was identified for this work at the provincial level as part of ongoing conversations related to scope of practice and models of care. Support at the provincial level was crucial to minimize any potential negative impact that may occur regarding competing organizational priorities. Nurses and other members of the interdisciplinary team working in the ACU also expressed a strong desire to clarify the role of the nurse, which was viewed as a key factor for facilitating staff engagement in project activities such as the proposed validation focus groups. The availability of the BCCNP and CANO standards and competencies as resources for both informing and completing the project work, as well as the results of the Care Team Design pilot, were also noted to be positive pre-existing factors that supported the project work.

\section{BARRIERS}

Several potential barriers were also identified, for which mitigation strategies needed to be considered to support successful completion of the project. Workload and staffing challenges in the clinic were identified as conceivable barriers that could impact the accessibility of front-line staff. Engagement with the clinical manager and front-line nurse leader early in the project to secure backfill for releasing staff to attend focus group sessions was key. Competing organizational priorities, such as Accreditation or the Clinical Systems Transformation project, also presented as discernible barriers to this project given the projected concurrent timelines. To avoid potential overlap that might result in project delays, a continuous review of the timelines and proposed activities for any competing initiatives was embedded into the project workplan. This afforded the opportunity to remain flexible and adjust the activities and timelines of the project as required to remain on target.

Another barrier identified was the LPN's limited scope in oncology. This may have represented a negative impact on LPN engagement in focus group validation work. Acknowledging the limited scope of LPN practice and messaging the projected outcomes of this project that support addressing scope and education in the medium term, served as the primary mitigation strategy for this potential barrier.

Lastly, the physical clinic space is small and busy, which could have represented a challenge in facilitating the observation assessments and process mapping exercises. To minimize the impact of project work in the physical space, clinic bookings for tentative observation days were reviewed in advance to assess for any higher than normal workload or inadequate staffing levels. The mitigation strategy was to observe on "typical" workload days that had a full complement of staff present.

\section{METHODS}

The key stakeholders identified for inclusion in the project work, which consisted of observation and focus group exercises, were the front-line nursing staff. The observational exercises took place over the course of four days and were used as the primary information gathering strategy for creating the preliminary baseline functional role elements list. During the observational exercise the clinical workflows of the nursing staff and activities performed to support direct patient care were documented. Process mapping of the workflows included the creation of detailed visual representations of the nursing functions supporting new patient, active treatment, and follow-up patient visits (Figure 1).

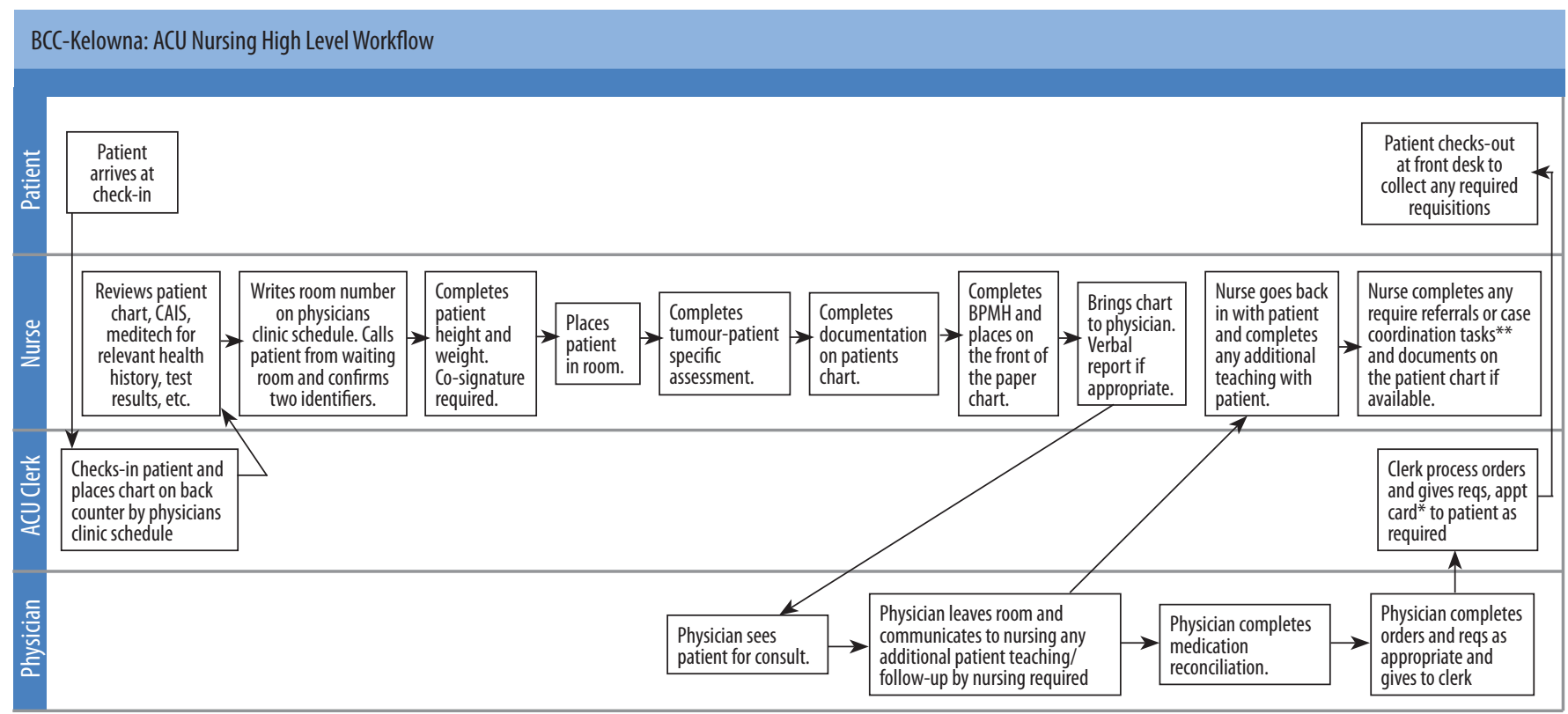

Figure 1: ACU nursing workflow process map. 
Two facilitated focus groups were then organized to obtain real-time feedback and validation of the compiled information. The first focus group was used to evaluate, refine and validate the preliminary baseline functional role elements list generated from the observation and process mapping exercise. Following completion of the first focus group, the validated baseline functional role element list was mapped against the BCCNP and CANO/ACIO standards to ensure the proposed activities aligned with best practice recommendations regarding meeting patient needs in the oncology setting (BCCNP, 2018a; BCCNPb, 2018b; BCCNP, 2018c; BCCNP, 2018d; CANOACIO, 2006; CANO-ACIO, 2017; CANO-ACIO, 2018). A second focus group was then held to evaluate and validate the proposed role-competency map with front-line staff.

\section{RESULTS}

As a result of the robust planning, observation and focus group exercises were successfully facilitated with front-line nursing staff to generate and validate a baseline functional role elements list and role-competency map (Table 3). A high-level workflow was also captured to understand the impact and challenges of integrating the wide variety of activities performed by nurses in the clinical context (Figure 1).

Each focus group session was attended by four to six frontline staff nurses who worked in the radiation and systemic therapy ACU clinics. Radiation Therapy (RT) staff nurses reviewed and validated the baseline functional role elements list and final role competency map created for the RT ACU which included 69 tasks. Similarly, the Systemic Therapy (ST) staff nurses participating in the focus groups reviewed and validated the parallel ST ACU documents, which included 58 tasks. The grouping of documents was further organized by clinical preparation tasks and appointment types (new patient, active treatment, and follow-up appointments) to encompass the distinct patient needs across the trajectory of their care. A segment of the validated role competency maps for RT and ST is presented in Table 3.

The verbal feedback elicited directly from staff participants and revealed the methods employed were perceived to be an appropriate and effective method to engage them in this foundational work. Overall, results of the project work included the identification of the current state of nursing roles and workflows, refinement and validation of the baseline functional role elements list, and completion of a fullsome role-competency map using the provincial and specialty nursing standards of practice.

\section{Limitations}

Limitations noted for this project include the overall project scope, ACU context, and resulting generalizability of the output documents. In considering the project scope, it was initially identified as optimizing the role of the nurse in the ACU context. While highly relevant and a gap that was supported by themes in the literature, the direct engagement with front-line staff identified a desire to optimize the roles of all members of the health care team in conjunction with this work; not just nursing. As such, it is recommended that the approach utilized in this project be repeated with other healthcare provider roles in the ACU to further enhance role clarity and optimize the interdisciplinary team model.

A second limitation related to the overall project scope is the focus on the BC Cancer-Kelowna context only. As previously mentioned, each of the six BC Cancer regional centres operate an ACU clinic, albeit with different models of care and nursing resources. While the results of this project may have the potential to impact decisions regarding ACU operations across BC Cancer, the differing models currently in place limit the generalizability of both the baseline functional role elements list and role-competency map across all sites. The differences necessitate validation of the project documents prior to adoption to ensure relevancy and applicability at the remaining five sites. The ACU context has also been identified as a limitation in this project as the items identified for both the baseline functional role elements list and role-competency map exist to nursing roles outside of the ACU clinic at BC Cancer-Kelowna. Like the desire we noted regarding optimizing roles across the interdisciplinary ACU team, front-line nursing staff indicated an interest in expanding this work to optimize the nursing role in other clinical areas. While this was determined to be out of scope for the purposes of this project, it has been identified as an area of focus for future phases of follow-up work.

\section{Recommendations}

Based on the satisfaction reported by front-line nurses and alignment with both provincial and specialty professional standards, it is recommended that the completed role-competency map be used as a foundation to inform future work on resource intensity weighting and the development of education for nurses. It is recommended that the resulting baseline functional role elements list and role-competency map undergo validation with front-line ACU nursing staff in each of the five remaining regional centres. Utilizing the approach employed in this project to optimize nursing roles in other clinics is also recommended. Stakeholders at both the provincial and regional levels should utilize the results of this project in strategic and operational planning discussions that are focused on improving health services for patients and supporting the continued professional development of front-line staff.

\section{CONCLUSION}

Defining and optimizing the role of the oncology nurse in the ACU environment will help provide role clarity and enable nursing to articulate both the scope of practice and the specialty competencies required to best meet the needs of our cancer patients and their families. However, there is a notable lack of formal research available in the literature on how to optimize the ambulatory oncology nurse role. Themes that were identified in the available literature to support optimization included the role of the nurse in the interdisciplinary team, dimensions of patient-centred care, and professional practice in oncology nursing. While further research in this area is still recommended, this QI project has provided a framework for oncology nurses to utilize their professional practice standards through the lens of patient needs to explore and articulate the role of the nurse on the interdisciplinary team. 
Table 3. Baseline/Role Competency Examples

\begin{tabular}{|c|c|c|c|c|}
\hline \multicolumn{2}{|c|}{ Baseline Functional Role Elements } & \multicolumn{3}{|l|}{ Standards } \\
\hline $\begin{array}{l}\text { Tumour specific follow-up } \\
\text { assessment } \\
\text { (Radiation and Systemic } \\
\text { Therapies) }\end{array}$ & $\begin{array}{l}\text { - See the clinic tumour } \\
\text { specific assessment } \\
\text { binder }\end{array}$ & $\begin{array}{l}\text { - Standard 1: Clinical } \\
\text { Practice Indicator } 4 \\
\text { - Standard 2: Clinical } \\
\text { Practice Indicators 1, 2, } \\
\text { 3, 4, 5, 6, 7, 11, 12, 13 } \\
\text { - Standard 3: Clinical } \\
\text { Practice Indicators 1, } \\
\text { 3, } 4 \\
\text { - Standard 4: Clinical } \\
\text { Practice Indicator } 7\end{array}$ & $\begin{array}{l}\text { - Standard 1: Indicator } 7 \\
\text { - Standard 2: Indicators } \\
\text { 1, 3, 4, 5, 6, 7, } 11 \\
\text { - Standard 3: Indicators } \\
\text { 1, 5, 6, 7, } 8 \\
\text { - Standard 4: Indicator } 6\end{array}$ & $\begin{array}{l}\text { - Domain 1: Competency } \\
\text { 1(a) } \\
\text { - Domain 2: Competencies } \\
\text { 2(j), 2(l) } \\
\text { - Domain 3: Competencies } \\
\text { 3(a), 3(b) } \\
\text { - Domain 4: Competencies } \\
\text { 4(a), 4(b) } \\
\text { - Domain 5: Competency } \\
\text { 5(e) } \\
\text { - Domain 7: Competency } \\
\text { 7(a) }\end{array}$ \\
\hline $\begin{array}{l}\text { Immunotherapy } \\
\text { Assessment } \\
\text { (Systemic Therapy) }\end{array}$ & $\begin{array}{l}\text { - Complete } \\
\text { immunotherapy } \\
\text { assessment based on } \\
\text { the patient's treatment } \\
\text { protocol and supporting } \\
\text { algorithms }\end{array}$ & $\begin{array}{l}\text { - Standard 1: Clinical } \\
\text { Practice Indicators 2, } 4 \\
\text { - Standard 2: Clinical } \\
\text { Practice Indicators - all } \\
\text { - Standard 3: Clinical } \\
\text { Practice Indicators 1, } \\
\text { 3, } 4 \\
\text { - Standard 4: Clinical } \\
\text { Practice Indicators 1, 7, } \\
\text { 10,13 }\end{array}$ & $\begin{array}{l}\text { - Standard 1: Indicator 2, } \\
\text { 4, 5, 6, 7, } 8 \\
\text { - Standard 2: Indicators } \\
\text { 1, 2, 3, 4, 5, 6, 7, 8, 9, } \\
\text { 10,11 } \\
\text { - Standard 3: Indicators } \\
\text { 1, 2, 5, 6, 7, } 8 \\
\text { - Standard 4: Indicators } \\
\text { 5, 7,10, } 11\end{array}$ & $\begin{array}{l}\text { - Domain 1: Competencies } \\
\text { 1(b), 1(c), 1(d). 1(e) } \\
\text { - Domain 3: Competencies } \\
\text { 3(a), 3(b) } \\
\text { - Domain 4: Competencies } \\
\text { 4(a), 4(b) } \\
\text { - Domain 5: Competency } \\
\text { 5(e) } \\
\text { - Domain 7: Competency } \\
\text { 7(a) }\end{array}$ \\
\hline $\begin{array}{l}\text { Palliative Care referrals } \\
\text { (Radiation and Systemic } \\
\text { Therapies) }\end{array}$ & $\begin{array}{l}\text { - Support the palliative } \\
\text { care conversation with } \\
\text { patient and family } \\
\text { members } \\
\text { - Complete \& submit } \\
\text { Palliative Care Program } \\
\text { documents } \\
\text { - Enrollment form } \\
\text { - Drug benefits } \\
\text { - Expected death at home } \\
\text { - Home care referrals } \\
\text { - MOST/ACP forms }\end{array}$ & $\begin{array}{l}\text { - Standard 1: Clinical } \\
\text { Practice Indicator } 4 \\
\text { - Standard 2: Clinical } \\
\text { Practice Indicators 2, 3, } \\
\text { 6, 7, 8, 10, 11, } 13 \\
\text { - Standard 3: Clinical } \\
\text { Practice Indicators 1, 2, } \\
\text { 3, 4, 6, 9, } 10 \\
\text { - Standard 4: Clinical } \\
\text { Practice Indicators 1, } \\
\text { 2, 5, 6, 7, 8, 9, 10, 11, } \\
\text { 12,13 }\end{array}$ & $\begin{array}{l}\text { - Standard 1: Indicator } 7 \\
\text { - Standard 2: Indicators } \\
\text { 2, 3, 6, 7, } 11 \\
\text { - Standard 3: Indicators } \\
\text { 1, 2, 3, 5, 6, } 8 \\
\text { - Standard 4: Indicators } \\
\text { 5, } 6\end{array}$ & $\begin{array}{l}\text { - Domain 2: Competencies } \\
\text { 2(i), 2(j), 2(k), 2(l; 7) } \\
\text { - Domain 3: Competencies } \\
\text { 3(a), 3(b), } 3 \text { (Palliative } \\
\text { Therapies) } \\
\text { - Domain 4: Competencies } \\
\text { - all } \\
\text { - Domain 5: Competencies } \\
\text { 5(a), 5(b), 5(c), 5(e), } \\
\text { 5(f), 5(g), 5(i), 5(k) } \\
\text { - Domain 6: Competencies } \\
\text { - all } \\
\text { - Domain 7: Competency } \\
\text { 7(a) }\end{array}$ \\
\hline
\end{tabular}

continued... 


\begin{tabular}{|c|c|c|c|c|}
\hline $\begin{array}{l}\text { Patient } \\
\text { Teaching- Protocols } \\
\text { (Systemic Therapy) }\end{array}$ & $\begin{array}{l}\text { - Print off protocol } \\
\text { specific patient } \\
\text { medication handouts } \\
\text { - Review medication } \\
\text { handouts with patient }\end{array}$ & $\begin{array}{l}\text { - Standard 1: Clinical } \\
\text { Practice Indicator } 4 \\
\text { - Standard 2: Clinical } \\
\text { Practice Indicators all } \\
\text { - Standard 3: Clinical } \\
\text { Practice Indicators 1, 3, } \\
\text { 4, 6, } 10 \\
\text { - Standard 4: Clinical } \\
\text { Practice Indicators 1, 2, } \\
6,7,10,11,12,13\end{array}$ & $\begin{array}{l}\text { - Standard 1: Indicator } 7 \\
\text { - Standard 2: Indicators } \\
\text { - all } \\
\text { - Standard 3: Indicators } \\
\text { 1, 2, 3, 5, 6, } 8 \\
\text { - Standard 4: Indicator } 6\end{array}$ & $\begin{array}{l}\text { - Domain 2: Competency } \\
\text { 2(a) } \\
\text { - Domain 3: Competencies } \\
\text { 3(a), 3(b), } 3 \text { (ST- a), } \\
\text { 3(b), } 3 \text { (ST- c), 3(d), } 3 \\
\text { (Other therapies- b), } 3 \\
\text { (Combined Modalities), } \\
3 \text { (Palliative Therapies), } \\
3 \text { (Symptom and Side } \\
\text { Effects Management- d), } \\
\text { 3 (Sexual health Issues- } \\
\text { a), 3 (Sexual health } \\
\text { Issues- b), 3 (Sexual } \\
\text { health Issues- c) } \\
\text { - Domain 4: Competencies } \\
\text { - all } \\
\text { - Domain 5: Competencies } \\
\text { 5(c), 5(e), 5(g), 5(h), 5(i) } \\
\text { - Domain 6: Competencies } \\
\text { 6(a), 6(i) } \\
\text { - Domain 7: Competency } \\
\text { 7(a) }\end{array}$ \\
\hline $\begin{array}{l}\text { Voiding Study } \\
\text { (Radiation Therapy) }\end{array}$ & $\begin{array}{l}\text { - Provides teaching } \\
\text { to patient regarding } \\
\text { purpose of test and how } \\
\text { to complete } \\
\text { - Complete and } \\
\text { document voiding study } \\
\text { results }\end{array}$ & $\begin{array}{l}\text { - Standard 1: Clinical } \\
\text { Practice Indicator } 4 \\
\text { - Standard 2: Clinical } \\
\text { Practice Indicators 1, 3, } \\
\text { 4, 5, 8, 10, 11, } 13 \\
\text { - Standard 3: Clinical } \\
\text { Practice Indicators 1, 2, } \\
\text { 3, 4, 6, 9, } 10 \\
\text { - Standard 4: Clinical } \\
\text { Practice Indicators 1, 2, } \\
\text { 5, 6, 7, 8, 9, 10, 13 }\end{array}$ & $\begin{array}{l}\text { - Standard 1: Indicator } 7 \\
\text { - Standard 2: Indicators } \\
\text { 1, 3, 4, 5, 6, 7, } 11 \\
\text { - Standard 3: Indicators } \\
\text { 1, 2, 3, 5, 6, } 8 \\
\text { - Standard 4: Indicator } 6\end{array}$ & $\begin{array}{l}\text { - Domain 1: Competency } \\
\text { 1(a) } \\
\text { - Domain 3: Competency } \\
3 \text { (Symptom and Side } \\
\text { Effects Management- b) } \\
\text { - Domain 4: Competency } \\
\text { 4(k; 7, 10) }\end{array}$ \\
\hline $\begin{array}{l}\text { Documentation } \\
\text { (Radiation and Systemic } \\
\text { Therapies) }\end{array}$ & $\begin{array}{l}\text { - Complete nursing } \\
\text { documentation on } \\
\text { approved forms as } \\
\text { required for all nursing } \\
\text { assessments, care, } \\
\text { interventions symptom } \\
\text { management and } \\
\text { teaching provided }\end{array}$ & $\begin{array}{l}\text { - Standard 1: Clinical } \\
\text { Practice Indicator } 4 \\
\text { - Standard 2: Clinical } \\
\text { Practice Indicators 7, } 11 \\
\text { - Standard 3: Clinical } \\
\text { Practice Indicators 1, 2, } \\
\text { 3, 4, 6, 9, } 10 \\
\text { - Standard 4: Clinical } \\
\text { Practice Indicators 1, 2, } \\
\text { 3, 4, 5, 6, 7, 8, 9, 10,13 }\end{array}$ & $\begin{array}{l}\text { - Standard 1: Indicator } 7 \\
\text { - Standard 2: Indicator } 6 \\
\text { - Standard 3: Indicators } \\
\text { 1, 2, 3, 5, 6, } 8 \\
\text { - Standard 4: Indicators } \\
\text { 5, } 6\end{array}$ & $\begin{array}{l}\text { - Practice Domain 2: } \\
\text { Competency 2(e) } \\
\text { - Practice Domain 6: } \\
\text { Competency 6(k) }\end{array}$ \\
\hline
\end{tabular}




\section{REFERENCES}

Azar, J. M., Johnson, C. S., Frame, A. M., Perkins, S. M., Cottingham, A. H., \& Litzelman, D. K. (2017). Evaluation of interprofessional relational coordination and patients' perception of care in outpatient oncology teams. Journal of Interprofessional Care, 31(2), 273-276. https://doi.org/10.1080/13561820.2016.1248815

Berglund, C. B., \& Gustafsson, E., Johansson, H., \& Bergenmar, M. (2015). Nurse-led outpatient clinics in oncology care - Patient satisfaction, information and continuity of care. European Journal of Oncology Nursing : The Official Journal of European Oncology Nursing Society, 19(6), 724-730.

BC Cancer (2018). BC Cancer Nursing Chemotherapy and Biotherapy Certification Program. http://www.bccancer.bc.ca/ health-professionals/education-development/nursing/ chemotherapy-certification-program

BC Children's \& Women's Hospital, BC Cancer, UBC Nurse Researchers (2018). Care Team Design Initiative. BC Cancer Internal Document Version 2, April 2018.

BC Government (2019). Information Privacy \& Security (FOIPPA). https://www2.gov.bc.ca/gov/content/governments/policiesfor-government/bcea-policy-and-procedure-manual/foippa/ information-privacy-and-security-foippa

BCCNP (2018a). Professional Standards for Licensed Practical Nurses. https://www.bccnp.ca/Standards/LPN/StandardResources/LPN_ ProfessionalStandards.pdf

BCCNP (2018b). Professional Standards for Registered Nurses and Nurse Practitioners. https://www.bccnp.ca/Standards/RN_NP/ StandardResources/RN_NP_ProfessionalStandards.pdf

BCCNP (2018c). Scope of Practice for Licensed Practical Nurses. https:// www.bccnp.ca/Standards/LPN/StandardResources/LPN_ ScopeOfPractice.pdf

BCCNP (2018d). Scope of Practice for Registered Nurses. https:// www.bccnp.ca/Standards/RN_NP/StandardResources/RN_ ScopeofPractice.pdf

Canadian Cancer Society (2018). Canadian Cancer Statistics: A 2018 Special Report on cancer incidence by stage. http://www.cancer.ca/ / media/cancer.ca/CW/cancer\%20information/cancer\%20101/ Canadian\%20cancer\%20statistics /Canadian-Cancer-Statistics2018-EN.pdf?la=en

Canadian Nurses Association (2012). Staff Mix: Decision-making Framework for Quality Care. https://cna-aiic.ca/ /media/cna/pagecontent/pdf-en/staff_mix_framework_2012_e.pdf

CANO-ACIO (2006). Practice Standards and Competencies for the Specialized Oncology Nurse. https://cdn.ymaws.com/ www.cano-acio.ca/resource/resmgr/standards/CONEP_ Standards2006September.pdf
CANO-ACIO (2017). Standards and Competencies for Cancer Chemotherapy Nursing Practice. https://cdn.ymaws.com/www.canoacio.ca/resource/resmgr/Resources/EN_CANO_Chemotherapy_ Standar.pdf

CANO-ACIO (2018). Radiation Oncology Nursing Practice Standards and Competencies. https://cdn.ymaws.com/www.cano-acio.ca/ resource/resmgr/standards/ronp_s\&c_web(2).pdf

Haas, S., Swan, B. A., \& Haynes, T. (2013). Developing ambulatory care registered nurse competencies for care coordination and transition management. Nursing Economic\$, 31(1), 44-43. http:// search.ebscohost.com/login.aspx?direct=true \&db=ccm\&AN=1080 26607\&site=ehost-live

Haas, S. A., Vlasses, F., \& Havey, J. (2016). Developing staffing models to support population health management and quality outcomes in ambulatory care settings. Nursing Economics, 34(3), 126-133. http://ezproxy.library.ubc.ca/login?url=https://search-proquestcom.ezproxy.library.ubc.ca/docview/1794904355?accountid=14656

Hagen B., O’Beorme M., Desai S., Stingl, M., Pachnowski C. A., \& Hayward S. (2007). Innovations in the ethical review of healthrelated quality improvement and research: The Alberta Research Ethics Community Consensus Initiative (ARECCI). Healthcare Policy, 2(4), 2-12. https://www.ncbi.nlm.nih.gov/pmc/articles/ PMC2585461/pdf/policy-02-e164.pdf

Health Professions Act (2018a). Nurses (registered) and nurse practitioners regulation. http://www.bclaws.ca/civix/document/id/ $\mathrm{crbc/crbc/2842008}$

Health Professions Act (2018b). Nurses (licensed practical) regulation. http://www.bclaws.ca/civix/document/id/crbc/ crbc/224_2015

Kaunonen, M., Salin, S., \& Aalto, P. (2015). Database nurse staffing indicators: Explaining risks of staff job dissatisfaction in outpatient care. Journal of Nursing Management, 23(5), 546-556. https://doi. org/10.1111/jonm.12169

Lee, C. T., Doran, D. M., Tourangeau, A. E., \& Fleshner, N. E. (2014). Perceived quality of interprofessional interactions between physicians and nurses in oncology outpatient clinics. European Journal of Oncology Nursing, 18, 619-625 https://doi-org.ezproxy. library.ubc.ca/10.1016/j.ejon.2014.06.004

More, L. (2017). Transition to practice - Part 2 implementing an ambulatory care registered nurse residency program: Competency - it's not just a task. Nursing Economic\$, 35(6), 317-326. http:// search.ebscohost.com/login.aspx?direct=true \&db=ccm\&AN=1268 65182\&site=ehost-live 